\title{
LETTERS-CONCISE RESEARCH REPORTS Acknowledging Intersectionality and Historical Context in Medical Education Research
}

J Gen Intern Med 35(10):3095

DOI: $10.1007 / \mathrm{s} 11606-020-06037-0$

(C) Journal of General Internal Medicine (This is a U.S. government work and not under copyright protection in the U.S.; foreign copyright protection may apply) 2020

$\mathrm{T}_{\mathrm{w}}$ o the Editors:

We read with interest the article by Chaitoff et al. entitled "The Effects of Student Demographic Characteristics in a Primary Care Encounter: a Randomized Experiment" published in the Journal of General Internal Medicine. ${ }^{1}$ The authors aimed to identify the association of patient and studentlevel predictors, specifically race and gender, with patients' comfort and willingness to be seen by a medical student.

We would like to acknowledge the challenge with stratification by race and gender separately. Given that student perspectives about discrimination by patients are a contributing factor to this study's hypothesis, it is important to note that experiences of discrimination can be simultaneously gendered and racialized. This has been shown in prior studies on the experience of Black women and men in the workplace, ${ }^{2}$ as well as the experience of Black boys and girls in schools. ${ }^{3}$ In fact, the now-commonly used term intersectionality was coined by legal scholar Kimberlé Crenshaw to capture the inextricable linkages between gender and race-based discrimination and their effects on the experiences of Black women. Many studies seek to identify the role gender and race play in medical trainees' experiences, but are limited in their methodological assessment of the critical interaction between their race and gender.

The study finds that Black respondents were less comfortable seeing any students. However, these findings are not contextualized in terms of historical and sociological context, leaving them up for interpretation. The history of discrimination against and abusive experimentation upon Black people in medical settings may explain the difference in comfort with seeing students, especially when the student was of a different race. ${ }^{4}$ Qualitative data could support said context and help avoid inadvertently portraying Black patients as difficult, or as barriers to student learning.

Received March 20, 2020

Accepted July 3, 2020

Published online July 23, 2020
As medical schools and teaching hospitals continue to make efforts to improve trainees' experiences related to discrimination, it is important that we acknowledge the ways in which perceptible markers of difference interact with each other (e.g., race and gender to find successful and innovative solutions). Furthermore, understanding patients' preferences with regard to working with trainees within a historical lens is paramount to developing adequate response and support strategies and ensuring equitable care for all patients. ${ }^{5}$

\author{
Max Jordan Tiako, $\mathrm{MS}^{1}$ \\ Sydney Green, BS ${ }^{1}$ \\ Utibe R. Essien, $M D, M P H^{2,3}$ \\ ${ }^{1}$ Yale School of Medicine, \\ New Haven, CT, USA \\ ${ }^{2}$ Division of General Internal Medicine, Department of \\ Internal Medicine, University of Pittsburgh School \\ of Medicine, \\ Pittsburgh, PA, USA \\ ${ }^{3}$ Center for Health Equity Research and Promotion, \\ VA Pittsburgh Healthcare System, \\ Pittsburgh, PA, USA
}

Corresponding Author: Utibe R. Essien, MD, MPH; Division of General Internal Medicine, Department of Internal Medicine, University of Pittsburgh School of Medicine Pittsburgh, PA, USA (e-mail: uessien@pitt.edu).

\section{REFERENCES}

1. Chaitoff A, Volovetz J, Mitchell-Handley B, et al. The Effects of Student Demographic Characteristics in a Primary Care Encounter: a Randomized Experiment. J Gen Intern Med (2020). https://doi.org/10.1007/s11606020-05681-w.

2. Wingfield, A. "Racializing the Glass Escalator: Reconsidering Men's Experiences with Women's Work." Gender \& Society, vol. 23, no. 1, Feb. 2009, pp. 5-26. https://doi.org/10.1177/0891243208323054.

3. Zimmermann, Calvin Rashaud, and Grace Kao. "Unequal returns to children's efforts: acial/ethnic and gender disparities in teachers' evaluations of children's noncognitive skills and academic ability." Du Bois Review: Social Science Research on Race 16.2 (2019):417-438.

4. Washington, Harriet A. Medical apartheid: The dark history of medical experimentation on Black Americans from colonial times to the present. Doubleday Books, 2006.

5. Paul-Emile, Kimani. "How Should Organizations Support Trainees in the Face of Patient Bias?." AMA journal of ethics 2019;21(6):513-520.

Publisher's Note: Springer Nature remains neutral with regard to jurisdictional claims in published maps and institutional affiliations. 